\title{
Connections and Abstractions: Blending Epistemologies of Love and Separation in Environmental Education
}

\author{
Małgorzata A. Dereniowska (Adam Mickiewicz University) \\ Jason P. Matzke (University of Mary Washington)
}

The seriousness and stubbornness of the ecological crisis and the realization that technological and political solutions provide, at best, limited solutions has led many to rethink environmental education with an eye towards changing deeply ingrained attitudes and behaviors. A transformed environmental education holds great promise for reshaping our relationship with the world around us rather than leaving this up to chance. The goal of environmental education can be realized, however, only by means of significant revision of our notions of nature and of human perception and learning. Citing widespread "illiteracy and ignorance about the natural world," Marion Gillian calls for the development of a "place-view;" education should foster a sense that "nature is [not] just another subject ... [but the] immanent context of our lives" (Gillian 1996, v and vi). But place-based education is not just about focusing students' attention on their immediate natural surroundings; advocates are quick to point out that it is also about moving beyond a singleminded focus on the so-called hard sciences to create a more holistic curriculum that would include field ecology, literature, poetry, art, and writing. These sentiments are echoed by Arthur Zajonc's call for an "epistemology of love" to replace the traditional "epistemology of separation." When love is understood not only as a romantic affair, but as an internal attitude toward the world, it changes our 
perspective on the learning process. Believing that only by loving what one studies can a person learn, Zajonc argues that environmental education should encourage a contemplative inquiry, intimacy, and participation (Zajonc 2006, 2) that can be realized by cultivating "a covert curriculum that educates for discovery, creativity, and social conscience" (Zajonc 2006, 8). After considering the arguments made in favor of a place-based and multi-, or trans-, disciplinary1 approach to environmental education-and largely agreeing with them-we will suggest that a more explicitly pluralistic approach is necessary and we illustrate by modifying Zajonc's notion of how to use his two contrasting epistemologies.

Place-based education, with its dual emphases of local place and multi- or trans-disciplinarity, is a challenge to traditional education and ways of knowing. Advocates of reform share a rejection of three components of traditional approaches to learning, and to environmental education more specifically: 1) The emphasis on science over the humanities and arts, 2) the distance created between knower and thing-to-be-known, and 3) the abstraction from particulars (e.g., place or culture) to the creation of general claims that are supposed to be true everywhere and always.

The arguments offered by place-based education proponents are not particularly complex, but they are, we think, important and largely correct. For instance, Jennifer Sahn, in her discussion of childhood education, argues that children must develop a sense of empathy for the names and details of nature to be absorbed; we should teach "hard facts" only after they develop an emotional connection with the natural around them (Sahn 1996, viii and ix). David Sobel cites the nature writer and poet, John Burroughs, to make the same point: "knowledge without love will not stick. But if love comes first, knowledge is sure to follow" (Sobel 1996, 10). Sobel continues by describing ways teachers, for example, can encourage a sense of connection prior to looking with students at books about bird identification. He suggests ways of moving from typical in-class, text-book exercises to outdoor experiential learning. Children can, for example, follow streams by launching handmade boats, they can clean debris from the banks, and they can test the thickness of ice in winter. Older students can engage in local policy debates, create recycling programs, and the like (Sobel, cf., 21, 23, 24, and 27). Sobel speaks of

\footnotetext{
1 "Interdisciplinary," "multi-disciplinary," and "cross-disciplinary" are various ways of referring to academic work that draws from a variety of perspectives while remaining largely consistent with the particular disciplines drawn from. Trans-disciplinary approaches are to go beyond the expectational limits of particular disciplines to create new genres, or at least work that is not necessarily identifiable as fitting within. The difference is probably more one of degree than kind. In any case, both approaches are thought to be superior to work done entirely within one discipline.
} 
having school children make and decorate wings from cardboard and dance as the birds they see on the schoolyard, of which he says, "and so we must begin in empathy, by becoming the animals before we can save them" (cf., 19).

In favor of this shift in approach, Sobel cites three scientific surveys and his own experience as an educator. For example, Louise Chawla's research regarding environmentalists' motivations for caring so much about nature indicates that they spent many childhood hours outdoors in more or less natural places with adults who cultivated a respect and admiration for things natural (cf., 10). Sobel believes this evidence points to the need for place-based education instead of a problems approach. Focusing on problems-especially distant ones (e.g., rainforest destruction)-instead of cultivating connections with the subject, leads to fear, a further distancing as a result of that fear, and eventually to disengagement as adults. The "problems approach" fails in part because young students are incapable of much abstraction, leading them to overly simplified conclusions such as that wild animals are good and bulldozer drivers are bad (cf., 28). This oversimplification does not prepare us to deal with the social and natural complexity that is at play in most cases of environmental destruction.

At this stage let us remark that Sobel's concern is primarily with elementaryaged school children. His aim is to convince teachers to think carefully about how they approach environmental education so as to not create fear-as he puts it, "No tragedies before the fourth grade" (cf., 27). He wants to encourage local placeoriented empathetic connections in order that children are not so emotionally overwhelmed that they lose interest in things ecological as they mature. However, his concerns and solutions are applicable to us adult learners and teachers of adult students as well. Worries of emotional disconnection, oversimplification, and general ecological ignorance are, after all, just as real for us adults as they are for younger learners. Witness, for example, how complex environmental issues are so often simplified by the media and politicians as "jobs vs. trees." Therefore, we need an account of a place-based approach that will embrace adult learning as well.

Place-based and trans-disciplinary environmental education has been problematized in the university setting by John Elder. ${ }^{2}$ Similarly to those focused

\footnotetext{
${ }^{2}$ It is notable that Elder gradually shifted his attention from teaching British Modernism in an English Department to the development of what is now the oldest environmental studies curriculum in the United States, begun in 1965. His move to a more interdisciplinary approach to learning grew out of both his interest in writers such as Thoreau, Wordsworth, and Frost and his location: Middlebury College in Vermont's heavily forested Green Mountains. The coming together of British and American nature writing and the flora, fauna, and geography of such a setting made place-based and trans-
} 
more on childhood education, Elder believes that we need to find ways to move away from the traditional science-heavy environmental education towards more environmentally attuned approaches: "without any stake in the places where we live, we walk through days in which there are trees but no tree in particular [and] we drive along roads that could be anywhere.... Such casual familiarity is the opposite of intimacy and attentiveness" (Elder 1998, 8). Place-based education is, though, only part of the answer. Science instruction might be improved by moving the classroom out of doors for certain lessons, but science seeks explanations that are generalizable-not specific or particular. Love and intimacy, on the other hand, with the natural (and for that matter, with each other) is necessary and cannot be developed through traditional science-placed-based or not-alone. Multi- or trans-disciplinarity is required as well.

The argument for place-based and trans-disciplinary education is made of two parts: the belief in the necessity of an emotional or sentimental attachment to an object of study (here, one's environment) and a rejection of the idea that science is the only, or best, route to knowledge and understanding. The first of these two argumentative parts is based on an oft-cited line from Aldo Leopold, who says, "it is inconceivable to me that an ethical relation to the land can exist without love, respect, and admiration for land, and a high regard for its value" (Elder, cf., 12). This is supported in philosophical discourse through the work of David Hume, who argued that it is not reason that lies at the heart of ethics, but our sentimental responses to each other, events, and the like. Reason alone, Hume points out, cannot motivate. It can help us clarify and sort out difficulties, but without both self- and other-oriented sentiments, we would have nothing resembling morality (Hume, 1998 [1751], 75-76). Thus any hope of long-term change with regard to how we interact with the environment must result in part from the fostering of empathy. Ethicist J. Baird Callicott argues that if Hume and Leopold are correct (and he thinks they are), the lessons of ecology and evolution should make us give up the "conquering Lord" image of humanity in exchange for one that sees us as intimately related to the rest of life; we are not the reason d'être of everything existing around us. Callicott argues that our other-oriented sentiments expand as we develop a sense of community with the rest of nature (Callicott 1999, 66-69).

disciplinary education a particularly attractive possibility. In an early course entitled "Visions of Nature," his students read English Romantic and American transcendentalist writers and studied the paintings and photography of Church, O'Keeffe, and Ansel Adams. Later he became one of the nonscientists recruited to teach alongside biologists, geologists, and geographers in the environmental studies major (Elder 1998, 2-6). 
The second point of the argument for place-based and trans-disciplinary education-i.e., the doubt that science is the only, or best, route to knowledge-is related to the first most directly in that non-scientific routes to understanding are thought to better create a sense of connection and empathy than can science alone. Underlying this is the observation that science seeks explicitly to understand the world in terms of universalizable "laws." As Elder puts it, the classical model's quest for knowledge is in contrast to a romantic or creative approach (cf., 12). Science, though, is not to be replaced, but supplemented. Elder sees trans-disciplinary placebased education as a way of endowing science with more meaning. His position is nicely illustrated in his recollection of his grandmother's wisdom: "When in ibis tucks its head underwing to sleep, it resembles a heart. The ibis knows empathy ... Remember that, alongside the fact that it eats worms." (cf., 13).

The above-mentioned contrast between the epistemologies of separation and of love provides some clarity for both elements of Elder's argument. Zajonc begins with the same realization that emotion-namely love-of one's object of inquiry is essential for depth of understanding to develop. Further, since "young people, who are beginners in everything, cannot yet know love, they have to learn it" (Zajonc 2006, 1). University environmental education must, then, through a variety of approaches slowly cultivate connection to place through literature, poetry, art, writing, and the like. In contrast to this epistemology of love, Zajonc sees traditional science as representing, or employing, an epistemology of separation. Because we are looking for a certain kind of knowledge-i.e., we want to know what the world is like independent of our human perspectives, values, and biases-we objectify the things we want to know about. We want to know what an ibis eats, not what this ibis eats. We want to understand how cancerous tumors grow and react to various external stimuli-not just these cancer cells-because only then can our knowledge translate into power to predict and manipulate. We have generally approached education, especially at the university level, in this way. The problem, however, is that when this approach is not tempered with other ways of knowing and being in the world, it leads to thinking about the world in ways merely instrumental and manipulative (Zajonc, cf., 2).

Thus, similarly to Elder and Sobel, Zajonc does not see the needed epistemology of love as a replacement for science. Although knowledge remains partial when we employ the objectifying epistemology of separation, "an epistemology of intimacy and participation, that is, an epistemology of love, . . . extends scientific and scholarly inquiry in ways that need not be ... problematic ... to our research disciplines" (cf., 2). That is to say that there are times appropriate for one or the other of these two general approaches to knowing; employing both 
provides a more holistic understanding. We do not want to lose, he argues, what we have gained in our embrace of the epistemology of separation (cf., 2). Elder likewise proclaims that he "revere[s] the scientific method, with its effort to arrive at unbiased and reproducible results, and its quest for a universal language," but he continues by saying that "the highest, and most trustworthy, science arises when the scientist is also capable of expressing in a personal voice the love that motivated his or her lifetime pursuit of knowledge about volcanoes or snakes or the origin of the universe" (Elder 1998, 10-11).

On both writers' view, there is a particular task to be completed by each way of knowing that makes both important without raising the worry of conflict. Zajonc (2006) makes the point through the use of the distinction between the context of discovery and of proof: "The 'context of proof' does indeed require careful assessment of insights against the data of experiments and the logic of mathematics. But the new insights of science enter as the fruit of contemplative gestation, not deductive analysis." (cf., 4). Philosophers of science usually call this the logic of discovery and the logic of justification. The process of discovery might include "long contemplative uncertainty" followed by flashes of creative realization. Zajonc notes that Heisenberg's breakthrough on quantum uncertainty took place while ill and fevered rather than through logical inferences upon data (cf., 4).

We agree that we have too long developed an epistemology of separation at the expense of fostering connection, empathy, and an attitude of community withas opposed to mastery over-the world around us. The primacy of instrumental reason has indeed led to the disenchantment of the world which, along with the exaltation of the individual and the attendant view of human beings as discrete and unattached, makes for little motivation to live and act in ways more congruous with other living things. We caution, though, against treating the two "epistemologies" as two completely separate methods of investigation. They do capture different attitudes, ways of seeing, or perspectives that we can employ as we seek to better understand ourselves and the world, and noting this can help us to move beyond the tempting but limiting focus on only one way of learning, or one way of seeing ourselves in the world. However, as is often the case with concepts and categories, we must not reify this dichotomy.

When one considers examples of discovery in science that seemingly support Zajonc's contention that the epistemology of love plays an important role in science, we note that it would be an oversimplification to describe discovery in terms of an epistemology of love and justification in terms of logic and abstraction. What we find instead are individuals who are engrossed in both, if not literally at the same time, then nearly so. Let us consider, for instance, the story told by Carl Hempel of 
the chemist Kekulé's struggle to understand the chemical structure of a benzene molecule. Kekulé, it is said, fell asleep in front of a fireplace and as he moved in and out of slumber saw snakes dancing in the flames. As one grabbed hold of its own tail Kekulé suddenly realized that the benzene molecule must be a hexagonal ring (Hemple 1996, 47). Hempel uses this story to illustrate the same point that Zajonc makes. However neither writer notes the fact that not everyone could have concluded the same thing that Kekulé did even had they the same dream. It was the mind's ability to move between - though again we do not mean to suggest a sharp dichotomy-the two ways of knowing that enable discoveries. As learners and teachers we must move with some fluidity between the two attitudes (and the attendant processes) without feeling that we are making cognitive shifts of such a magnitude that we cannot do-in our own scale-what Kekulé could do. The difficulty will be that there are no obvious rules about how or when, or in what way, a person should blend or develop both ways of learning and knowing.

The relationship between the two attitudes can be seen elsewhere as well. For example, Henry David Thoreau observed that the shore of Walden Pond was laid with regularly shaped stones due to waves eroding the surrounding land that was mixed with such stones. But upon solving this question he adds, interestingly, that, "unfortunately, it is no longer a mystery to me" (Thoreau 1985 [1854], 468). Similarly, while traveling to Maine's Mt. Katahdin he remarks upon being amazed by discovering phosphorescent wood that, "A scientific explanation ... would have been altogether out of place here. That is for pale daylight. Science with its retorts would have put me to sleep; it was the opportunity to be ignorant that I improved." (Thoreau, 1985 [1864], 731-732). Nonetheless, despite his claim that sometimes science gets in the way of us fully aesthetically or emotionally appreciating something, he nonetheless spent the greater part of his life trying to better understand the natural history, patterns, and processes of the natural world.

John Muir had fewer doubts about the value of science, arguing explicitly that it helps us appreciate and connect with the world around us. Importantly, both men were aware of the different ways in which one understands, but neither saw them as sharply distinct. Muir, for example, was engaged with the world around him in Yosemite Valley (California) as both an amateur scientist-measuring, modeling, and testing hypotheses - and a nature mystic. In his attempts to better understand how Yosemite Valley was formed, Muir blended the two ways of seeing harmoniously. Not only did he carefully measure detritus fields and sketch the direction of glacial groves in the rock, but he felt and imagined: "Here I lay down and thought of the time when the groove in which I rested was being ground away 
at the bottom of a vast ice-sheet that flowed over all the Sierra like a slow wind" (Badè 1924, 311).

After describing the examples of the combined epistemologies at play, the advantages of place-based and trans-disciplinary learning seem clear. And learning about the world around us should involve the development of connectedness and creativity, on the one hand, and careful empirical work of the sort emphasized in the epistemology of separation, on the other. In moving beyond the traditional focus on the objectification of the objects of study, we end up studying local environment as our inhabited place in a way that allows embodied engagement and emotional connection. As Leopold and Callicott believed, we can foster the idea that we are part of nature instead of separate, which becomes easier when we remember that nature is home, and home is something we are emotionally connected to in a quite particular way. Place-based education should embrace literature, philosophy, poetry while at the same time studying and using the scientific method and conclusions of ecology, chemistry, biology. There are differences of disciplinary approach, but if we help students see connections this potentially aids in teaching them to move fluidly between ways of understanding instead of treating different disciplines as sharply distinct. That is, a holistic image will not, in fact, emerge for students who merely read literature or engage in artwork while studying ecology. There are some ways of mitigating this worry, though it is important to realize that the sort of complete learning that we are advocating is not the sort that fits neatly into a set of definable and prescriptive pedagogical formulas. What we should be doing is providing students with enough of an idea of how to think creatively while thinking analytically, or how to engage aesthetically while also doing so systematically, so they might continue to learn in this way long after leaving the halls of academia. The particulars of how this should work will be left to the education experts, but we do want to offer one additional argument in favor of the trans-disciplinary approach.

Zajonc's use of the epistemologies of separation and love is just one way in which we might conceptualize the awareness that traditional science alone provides a quite limited perspective. Another way is suggested when we notice how fully we rely on models and metaphors that are at once incomplete, incommensurable, and yet essential. Models and metaphors are necessary for the simple reason that we do not possess anything resembling a monistic account of the world; models and metaphors help us as we focus on a particular topic because they give us a background against which to understand without requiring that we know all the details of that background. For example, discussions of predator/prey relationships can take place using the model of undulating but stable populations despite the fact that many ecologists reject this model as an accurate description of ecosystems. But 
yet, it is a useful model or metaphor because it allows discussions of predator/prey relationships without requiring the inclusion of complex dis-equilibrium models.

Bryan Norton and Douglas Noonan advance the idea that learning and understanding requires embracing multiple but singly incomplete and sometimes incommensurable models and metaphors by pointing out that while ecosystems can be thought of as production systems (i.e. systems that produce goods and services that we human beings like and need), they can also be conceptualized in numerous other ways, such as Leopold's community of mutually interrelated beings and resources. The model or metaphor we choose is relative to our interests. As Norton and Noonan observe, "The choice of an appropriate metaphor is not a matter of uncertainty that may be remedied by more data-it is instead a choice of a guiding metaphor which, in turn, highlights some values and hides others" (Norton and Noonan 2007, 670). When we choose to think of ecosystems as production systems for human goods, we also are deciding "not to employ alternative metaphors that would highlight alternative pathways and alternative values." Leopold himself, Norton and Noonan argue, used multiple metaphors to conceptualize the human relationship with the natural world-three temporal scales of the micro-human perception, ecological time, and geological time-that involve radically different ecological and evolutionary perspectives (Norton and Noonan 2007, 670).

The point for us here is that as we move between different epistemologies, or ways of understanding and learning, we should remember that we are employing metaphors and models that are not simply pieces of some larger whole, but are different ways of seeing the same thing. Trans-disciplinarity that draws from a variety of perspectives has the potential to provide us with richer-even if not neatly holistic-understandings of the world.

\section{Bibliography}

Badè, W. 1924. The Life and Letters of John Muir, Vol. 1. Boston: Houghton Mifflin Company.

Callicott, J. 1999. Beyond the Land Ethic: More Essays in Environmental Philosophy. Albany, New York: State University of New York Press.

Elder, J. 1998. Teaching at the Edge. Stories in the Land: A Place-Based Environmental Education Anthology. Great Barrington, Mass.: The Orion Society.

Gilliam, M. 1996. The Nature Literacy Series. In: Sobel, 1996, v-vii.

Hemple, C. 1996. The Role of Induction in Scientific Inquiry. In: T. Schick, Jr. (Ed.), Readings in the Philosophy of Science: From Positivism to Postmodernism. Mountain View, Calif.: Mayfield Publishing Company 2000. 
80 I Małgorzata A. Dereniowska, Jason P. Matzke

Hume, D. 1998 [1751]. An Enquiry Concerning the Principles of Morals. T. Beauchamp (Ed.). Oxford: Oxford University Press.

Norton, B. \& Noonan, D. 2007. Ecology and Valuation: Big Changes Needed. Ecological Economics 63: 664-675.

Sahn, J. 1996. Introduction. In: Sobel, 1996, viii-x.

Sobel, D. 1996. Beyond Ecophobia: Reclaiming the Heart in Nature Education. Great Barrington, Mass.: The Orion Society.

Thoreau, H. 1985 [1854] and [1864]. Henry David Thoreau: A Week on the Concord and Merrimack Rivers / Walden; Or, Life in the Woods / The Maine Woods / Cape Cod. New York: Library of America.

Zajonc, A. 2006. Cognitive-Affective Connections in Teaching and Learning: The Relationship Between Love and Knowledge. Journal of Cognitive Affective Learning (3.1): 1-9. 
Małgorzata A. Dereniowska (Adam Mickiewicz University, Poznań, Poland)

Jason P. Matzke (University of Mary Washington Fredericksburg, Virginia, USA)

\title{
Connections and Abstractions: Blending Epistemologies of Love and Separation in Environmental Education
}

\begin{abstract}
Understanding the epistemological dimension of the subject-object dichotomy is crucial for environmental learning. Contrasting the epistemologies of separation and love, Arthur Zajonc argues that learning is seriously limited unless we focus more attention on fostering deep connections of respect, love, and participation with the objects we study. Although an attitude of detachment and objectivity is sometimes appropriate, understanding such things as social justice and the environment demand an approach that softens the sharp dichotomy between knower and thing-to-be-known. While largely agreeing with Zajonc, we emphasize that the epistemologies of separation and love should not be seen as wholly distinct or unrelated. A deep understanding of ourselves and the world around us depends upon a shifting back and forth between these approaches, though this will, admittedly, not be susceptible to any strict set of methodological rules. Learning depends upon not only understanding how to use these two epistemologies, but, importantly, learning how to shift between them with ease. Furthermore, we suggest that Zajonc's use of the dual concepts of the logic of discovery and of justification to illustrate his two epistemologies can be made more descriptively accurate and prescriptively useful by noticing that in the process of learning-of discovering-investigators can and do move fluidly between seeking detached objectivity and connectedness. We embrace a broad pedagogical approach to environmental education consistent with Zajonc's view and that is place-based and multi- and transdisciplinary. This includes a rejection of the priority of science over the humanities, a narrowing of the gap between knower and thing-to-be-known, and a move away from attempts to excessively abstract from particulars to generalities and laws.
\end{abstract}

Keywords. Environmental learning, place-based education, epistemology of love, epistemology of separation, trans-disciplinarity.

Citations. Reference this paper as: Dereniowska, M., Matzke, J. P. (2012). Connections and Abstractions: Blending Epistemologies of Love and Separation in Environmental Education. Ethics in Progress Quarterly, Volume 3, Issue 1, pp. 71-81, available online at ethicsinprogress.org. 